\title{
Influência de fungos micorrízicos-arbusculares em paricá (Schizolobium amazonicum) cultivado no estado do Pará
}

\author{
Vanderlene Brasil Lucena1 ${ }^{1}$ Milena Pupo Raimam¹, Nerio Aparecido Cardoso², Ulisses Brigatto Albino² \\ ${ }^{1}$ Unidade de Ensino Superior do Sul do Maranhão, Rua São Pedro, 11, CEP 65907-070, Imperatriz, MA, Brasil \\ ²Universidade Federal do Pará, Faculdade de Ciências Biológicas, Rua Coronel José Porfírio, 2515, CEP 8372-040, Altamira, PA, Brasil
}

\author{
"Autor correspondente: \\ ualbino@ufpa.br \\ Termos para indexação: \\ Crescimento vegetal \\ Silvicultura \\ Espécies amazônicas \\ Microbiologia \\ Index terms: \\ Plant growth \\ Forestry \\ Amazonian species \\ Microbiology
}

Histórico do artigo:

Recebido em 11/04/2012

Aprovado em 26/09/2013

Publicado em 30/09/2013

doi: 10.4336/2013.pfb.33.75.386
Resumo - Este trabalho objetivou verificar a presença e a influência de fungos micorrízico-arbusculares (FMA) em plantas de Schizolobium amazonicum em plantios comerciais na região Tocantina, estado do Pará. Plantas com um ano de idade foram avaliadas em campo, sendo selecionadas as 10 mais desenvolvidas e as 10 menos desenvolvidas. Para cada planta foi medida a altura, a maior circunferência do caule e contado o número de folhas. Ao mesmo tempo, amostras de solo rizosférico foram colhidas na projeção da copa. As amostras foram analisadas quanto ao teor de matéria orgânica, $\mathrm{pH}$ em $\mathrm{CaCl}_{2}$ e presença de hifas, vesículas, arbúsculos e esporos nas raízes finas. Foi realizada ainda a extração de esporos do solo, por centrifugação em solução de sacarose, utilizados para inoculação de plântulas de $S$. amazonicum em casa de vegetação. Foram constatadas correlações positivas entre as estruturas fúngicas internas das raízes e os parâmetros medidos nas plantas em campo. Em casa de vegetação a inoculação de esporos aumentou significativamente o crescimento em altura das plântulas.

\section{Influence of arbuscular-mycorrhizal fungi in paricá (Schizolobium amazonicum) grown on Pará State, Brazil}

\begin{abstract}
The aim of this study wasto determine the presence and influence of Arbuscular-mycorrhizal fungi (AMF) in a stand of Schizolobium amazonicum trees on Tocantina region, Pará State, Brazil. One year old trees, were evaluated in the field by a team that chose the 10 most developed and the 10 less developed individuals. Height, greater circumference of the stem and leaf number were measured for each tree. At the same time, rhizosphere soil samples were collected at the canopy projection. Samples were analyzed for organic matter content, $\mathrm{CaCl}_{2} \mathrm{pH}$ and presence of hyphae, vesicles, arbuscules and spores in the fine roots. We carried out further soil AMF spores extraction by centrifugation in a sucrose solution which was used for inoculation of S. amazonicum seedlings in a greenhouse. Positive correlations between fungal structures inside the roots and plant measured parameters were verified. Spores inoculation increased significantly height grown of seedlings in greenhouse.
\end{abstract}




\section{Introdução}

O cultivo de espécies florestais nativas é uma alternativa econômica viável, de menor impacto ambiental frente às culturas exóticas e que reduz a pressão sobre áreas de mata nativa, sobretudo nas regiões Norte e Nordeste do Brasil. Uma espécie que tem mostrado potencial na Região Amazônica é o Paricá (Schizolobium amazonicum Huber ex Ducke) árvore que ocorre em mata primária e secundária de terra-firme e várzea alta, apresentando rápido crescimento (Ducke, 1949). É uma espécie heliófila caesalpinaceae, de grande porte, podendo alcançar $30 \mathrm{~m}$ de altura. Sua madeira é utilizada na fabricação de compensados, celulose e laminados.

A espécie tem sido cultivada na região de Dom Eliseu e Rondon do Pará, PA, sendo colhida com idades entre seis a oito anos, rendendo até $150 \mathrm{~m}^{3} \mathrm{ha}^{-1}$. Pelas características da madeira, a planta cultivada apresenta maior valor comercial que as nativas (Albino, 2012). Por ser planta pioneira na floresta tropical, é indicada para compor sistemas agroflorestais (SAFs), principalmente associado a café (Jaramillo-Boteroet al., 2008) e cacau (Rondon, 2002).

Em plantas pioneiras, a demanda por nutrientes é alta, devido à elevada taxa de crescimento (Zangaro et al., 2003), tornando o cultivo de espécies como $S$. amazonicum caro e nem sempre possível, além do que, a introdução de fertilizantes sintéticos em ambientes já perturbados aumenta a degradação, acarretando problemas maiores aos ecossistemas.

Uma boa alternativa é buscar na natureza microrganismos que vivem em associação com as plantas, melhorando sua nutrição e protegendo contra pragas e doenças (Albino et al., 2006). Dentre as diversas relações biológicas existentes, destacam-se as micorrizas arbusculares (FMAs), as quais são cosmopolitas e de grande importância nos ecossistemas tropicais, com eficácia comprovada em espécies arbóreas cultivadas em áreas degradadas ou com carência de nutrientes específicos (Lins et al., 2007).

Os fungos FMAs trazem benefícios à comunidade vegetal e ao ambiente, fornecendo nutrientes e água às plantas, assim como agregação e estabilidade dos solos (Augé et al., 2001). Assim, estes fungos têm sido estudados visando a sua aplicação no desenvolvimento e na produção das culturas, mediante seus efeitos na nutrição das plantas e outros benefícios, como a proteção contra patógenos. No entanto, existem obstáculos a isto, como adaptação aos fatores edáficos e competição com fungos nativos, que podem comprometer a eficácia simbiótica dos FMA introduzidos na inoculação (Balakrishna et al., 1996).

Siviero et al. (2008) avaliaram o desempenho de S. amazonicum em plantio comercial com e sem a inoculação de bactérias fixadoras de nitrogênio e fungos micorrízico-arbusculares já consagrados pelo uso em outras culturas, obtiveram aumentos de produção de biomassa, apesar de discretos, sobretudo quando foi aplicado FMA e bactérias fixadoras de nitrogênio juntos.

A seleção de fungos FMA já adaptados ao Paricá pode ser uma alternativa vantajosa em cultivos comerciais ou de recomposição florestal, trazendo como benefícios a diminuição do uso de fertilizantes sintéticos, promovendo economia financeira e menor contaminação ambiental.

O objetivo deste trabalho foi investigar a presença e a influência de associações micorrízicas em raízes de plantas cultivadas de paricá e o seu potencial em reduzir o uso de insumos de síntese química, principalmente de fertilizantes, contribuindo para um reflorestamento ecológico, numa perspectiva de preservação ambiental e aumento da produção para cultivo comercial.

\section{Material e métodos}

A seleção das plantas e coleta de material foi realizada na fazenda Bananal, BR $222 \mathrm{Km} \mathrm{70,} \mathrm{município} \mathrm{de}$ Rondon do Pará, PA. O plantio de 1 ano foi percorrido por uma equipe que atribuiu notas para 20 plantas a fim de se comparar árvores bem desenvolvidas com árvores pouco desenvolvidas em uma área de $10 \mathrm{ha}$. As menores plantas encontradas receberam notas de 1 a 10 e as melhores plantas receberam notas de 11 a 20, formandose então dois grupos. Foram analisados a altura, a maior circunferência do caule e o número de folhas.

De cada planta avaliada foi coletada uma amostra de solo rizosférico, composta de três sub-amostras tomadas na projeção da copa ao redor da árvore utilizando-se enxadão, de modo a não destruir as raízes finas.

Em laboratório, o solo rizosférico foi submetido às análises químicas: teor de matéria orgânica e $\mathrm{pH}$ em $\mathrm{CaCl}_{2}$. Para avaliação da quantidade de matéria orgânica, $10 \mathrm{~g}$ de terra seca peneirada, de cada amostra foram submetidos a combustão em forno mufla a $600{ }^{\circ} \mathrm{C}$ por $48 \mathrm{~h}$. Após o resfriamento e nova pesagem, a massa perdida foi considerada a correspondente ao teor de matéria 
orgânica. $5 \mathrm{~g}$ de cada amostra de terra foram suspensos em $10 \mathrm{~mL}$ de solução $\mathrm{CaCl}_{2} 0,01 \mathrm{~mol} \mathrm{~L}^{-1}$, agitadas em agitador rotacional Shaker e após descansarem por $1 \mathrm{~h}$ tiveram o $\mathrm{pH}$ registrado em medidor de $\mathrm{pH}$ de bancada da marca HANNA, modelo Q-400 HM.

Para as análises biológicas, raízes finas foram separadas de cada amostra com a terra ainda fresca e submetidas ao método de coloração de Phillips \& Haymam (1970). Após a coloração, foram montadas lâminas de microscopia com $10,0 \mathrm{~cm}$ de raízes cada e estas analisadas quanto à presença de fungos micorrízicos-arbusculares contandose as estruturas hifas, vesículas, arbúsculos e esporos por centímetro de raiz.

A extração de esporos micorrízicos foi realizada por peneiramento úmido de $10 \mathrm{~mL}$ de solo de cada amostra, seguido de centrifugação em solução de sacarose a $40 \%$. Após a centrifugação, o sobrenadante foi filtrado em papel de filtro quadriculado que permitiu a contagem e a separação dos morfotipos sob o microscópio estereoscópico. Os diferentes morfotipos foram suspensos em solução salina $(\mathrm{NaCl} 0,85 \%)$ em tubos plásticos e armazenados para experimentos em casa de vegetação.

Foram produzidas mudas de Schizolobium amazonicum a partir de sementes desinfectadas com álcool $70 \%$ e hipoclorito a $5 \%$, germinadas em vasos de cerâmica de dois litros de volume, contendo terra de barranco peneirada e esterilizada em vapor fluente. Em casa de vegetação, as mudas foram dispostas de modo casualizado e receberam os tratamentos: somente terra (controle); 5 g de NPK 10-28-20 por vaso; 30 esporos micorrízicos por vaso, com 12 repetições de cada tratamento. Dos esporos separados nas amostras de solo, foi utilizado somente o morfotipo mais abundante, um esporo de coloração castanha. Trinta esporos foram separados em 12 tubos plásticos imersos na solução salina estéril. A solução foi trocada e os tubos centrifugados 3 vezes com intuito de se reduzir a microbiota pré existente nestes esporos, uma vez que foram extraídos diretamente do solo coletado em campo. A irrigação foi feita com água destilada, evitando respingos de um vaso a outro. As plântulas foram analisadas 45 dias após a emergência.

Após as análises químicas e biológicas do solo, os parâmetros foram confrontados visando relacionar os parâmetros químicos e biológicos do solo e micorrizas com o desenvolvimento da parte aérea da planta. Os dados avaliados foram a altura da planta desde a interface solo/ar até a gema apical, o número de folhas, o diâmetro do caule na interface solo/ar, a massa seca da parte aérea e a massa seca do sistema radicular. Uma porção de raízes de cada plântula foi submetida à coloração para confirmação da infecção pelo fungo micorrízico.

Atendidos os pressupostos de normalidade, homocedasticidade e independência residual através dos testes de Shapiro Wilks, F e Durbin-Watson, respectivamente, os dados obtidos com o experimento em casa de vegetação (altura, número de folhas, peso da raiz e peso da parte aérea) foram submetidos à análise de variância (ANOVA). Obtidos resultados significativos no quadro de ANOVA, foi realizado o teste de Duncan a $95 \%$ de confiabilidade para se comparar os contrastes (Montgomery, 2001; Barbosa, 2000). Os dados obtidos com as plantas e solo em campo (altura, circunferência, número de folhas, matéria orgânica, $\mathrm{pH}$, hifas, vesículas, esporos totais e arbúsculos foram submetidos à análise de correlação de Spearman ao nível de 95\% de confiabilidade (Zar, 1999). As análises mencionadas foram realizadas através do software " $R$ " (R Development Core Team, 2006).

\section{Resultados}

As medidas das plantas numeradas de 1 a 20 em campo, os valores dos parâmetros relacionados à associação com fungos micorrízicos e os aspectos químicos $\mathrm{pH}$ e porcentagem de matéria orgânica do solo rizosférico analisado são apresentados na Tabela 1. Foram observados quatro morfotipos de esporos micorrízicos. O morfotipo mais abundante, um esporo de cor castanho claro, foi o selecionado para inoculação nas plântulas de S. amazonicum em casa de vegetação. A identificação do fungo micorrízico formador deste esporo apontou a espécie Glomus microcarpum, descrito por Gerdemann \& Trappe (1974).

As variáveis quantitativas analisadas foram confrontadas (Tabela 2) de modo a se destacar as interações que apresentaram de correlação.

De acordo com a análise de correlação de Spearman (Tabela 2), o parâmetro altura teve correlação positiva significativa com o teor de matéria orgânica no solo $(\mathrm{r}=0,51)$ e com o parâmetro $\mathrm{pH}$ do solo $(\mathrm{r}=0,42)$, indicando que $\mathrm{pH}$ mais elevado e maiores teores de matéria orgânica no solo (Tabela 1) favorecem o crescimento vertical desta planta. O parâmetro altura, quando confrontado com número de esporos no solo rizosférico mostrou correlação negativa $(r=-0,42)$, ou seja, nas plantas mais altas os fungos micorrízicos estão produzindo menos esporos. 
A circunferência do tronco (rodo), apresenta correlação positiva baixa, mas significativa, com os parâmetros matéria orgânica $(\mathrm{r}=0,35)$ e $\mathrm{pH}$ do solo $(\mathrm{r}=$ 0,36 ), correlação negativa com o número de esporos no solo $(r=-0,58)$ e correlação baixa, positiva e significativa com o número de arbúsculos por centímetro de raiz.

O número de folhas na planta, característica importante nas primeiras fases, por sombrear o solo e garantir aporte de energia, apresentou correlação positiva forte com o parâmetro $\mathrm{pH}$ do solo $(\mathrm{r}=0,56)$. O número de folhas na planta também é inversamente proporcional à quantidade de esporos no solo $(\mathrm{r}=-0,45)$. Quanto às estruturas fúngicas analisadas, confrontadas entre si, o número de hifas por centímetro de raiz apresentou correlação positiva com o número de vesículas $(\mathrm{r}=0,62)$.

A inoculação de esporos FMA nativos em plantas cultivadas em casa de vegetação (Tabela 3 ) demonstrou vantagem significativa na altura das plantas inoculadas comparadas ao controle e às plantas adubadas quimicamente. Enquanto as plantas adubadas apresentaram média de $17 \mathrm{~cm}$ de altura e as plantas controle $17,83 \mathrm{~cm}$, as inoculadas apresentaram média de $20,67 \mathrm{~cm}$, diferença significativa ao nível de 5\% do teste de Duncan. Apesar de não significativo, a inoculação de FMA proporcionou diminuição no peso das raízes (Tabela 3 ). O coeficiente de variação $(\mathrm{CV})$ entre as plantas analisadas foi relativamente elevado nos parâmetros número de folhas, massa de raiz e massa aérea (Tabela 3), possivelmente porque as plântulas analisadas neste trabalho foram obtidas com sementes colhidas na natureza, as mesmas utilizadas nos plantios, provenientes de áreas de florestas nos estados do Acre e Rondônia, com elevada variabilidade que se observa também nos plantios.

Tabela 1. Características das plantas analisadas, solo rizosférico e aspectos da associação micorrízica em Schizolobium amazonicum cultivado no estado do Pará.

\begin{tabular}{cccccccccc}
\hline Nota & $\begin{array}{c}\mathbf{N}^{\mathbf{0}} \mathbf{d e} \\
\text { folhas }\end{array}$ & $\begin{array}{c}\text { Circunferência } \\
(\mathbf{c m})\end{array}$ & $\begin{array}{c}\text { Altura } \\
\mathbf{( c m})\end{array}$ & Hifas & $\begin{array}{c}\mathbf{N}^{\mathbf{0}} \mathbf{d e} \\
\text { vesículas }\end{array}$ & $\begin{array}{c}\mathbf{N}^{\circ} \mathbf{d e} \\
\text { esporos }\end{array}$ & $\begin{array}{c}\mathbf{N}^{\mathbf{0}} \mathbf{d e} \\
\text { arbúsculos }\end{array}$ & $\begin{array}{c}\text { Matéria } \\
\text { orgânica } \\
\mathbf{( \% )}\end{array}$ & $\mathbf{p H}$ \\
\hline 1 & 13 & 5 & 170 & 4,0 & 1,1 & 51,0 & 1,4 & 15,9 & 4,9 \\
2 & 9 & 9 & 200 & 2,2 & 0,0 & 28,0 & 0,0 & 16,1 & 3,3 \\
3 & 11 & 9 & 250 & 8,7 & 1,9 & 34,0 & 0,2 & 16,3 & 5,4 \\
4 & 14 & 12 & 250 & 5,1 & 1,0 & 25,0 & 1,1 & 16,3 & 4,8 \\
5 & 15 & 16 & 280 & 1,4 & 2,0 & 29,0 & 1,9 & 17,0 & 4,3 \\
6 & 19 & 12 & 300 & 10,1 & 2,8 & 42,0 & 0,1 & 21,7 & 5,1 \\
7 & 15 & 13 & 350 & 6,0 & 2,8 & 54,0 & 0,9 & 17,4 & 4,1 \\
8 & 13 & 14 & 350 & 3,6 & 1,0 & 40,0 & 0,7 & 34,3 & 3,1 \\
9 & 15 & 16 & 350 & 9,6 & 3,0 & 29,0 & 0,2 & 16,0 & 3,8 \\
10 & 22 & 18 & 370 & 9,1 & 2,2 & 23,0 & 0,1 & 14,5 & 3,5 \\
11 & 23 & 18 & 370 & 3,4 & 2,4 & 27,0 & 0,4 & 18,2 & 5,4 \\
12 & 30 & 24 & 460 & 10,3 & 5,7 & 26,0 & 0,4 & 15,6 & 6,2 \\
13 & 22 & 21 & 480 & 10,8 & 11,0 & 10,0 & 1,0 & 21,8 & 4,8 \\
14 & 25 & 24 & 500 & 4,7 & 1,0 & 16,0 & 0,6 & 17,6 & 5,9 \\
15 & 27 & 29 & 500 & 5,8 & 2,7 & 10,0 & 1,9 & 17,6 & 4,0 \\
16 & 29 & 23 & 510 & 0,4 & 0,7 & 33,0 & 0,3 & 27,6 & 5,3 \\
17 & 29 & 27 & 510 & 8,8 & 0,1 & 36,0 & 0,9 & 20,2 & 5,6 \\
18 & 30 & 28 & 510 & 0,0 & 1,0 & 21,0 & 0,0 & 18,0 & 4,6 \\
19 & 27 & 26 & 600 & 7,4 & 6,5 & 30,0 & 1,3 & 18,8 & 5,3 \\
20 & 32 & 29 & 620 & 9,8 & 1,3 & 12,0 & 2,1 & 20,9 & 6,0 \\
\hline
\end{tabular}

Nota que a planta recebeu em campo, número de folhas por planta, maior circunferência do caule $(\mathrm{cm})$, altura da planta $(\mathrm{cm})$, número de vesículas micorrízicas por centímetro de raiz, número de esporos em $10 \mathrm{~mL}$ de solo, número de arbúsculos por centímetro de raiz, porcentagem de matéria orgânica e pH em cloreto de cálcio. 
Tabela 2. Confronto da análise de correlação dos dados obtidos para 20 plantas de Schizolobium amazonicum, em povoamento com um ano de idade, quanto às estruturas micorrízicas presentes nas raízes (hifas, vesículas, esporos totais e arbúsculos), características da planta (altura, circunferência e número de folhas) e análise parcial de solo (matéria orgânica e pH).

\begin{tabular}{|c|c|c|c|c|c|c|c|c|c|}
\hline & Altura & Circunferência & Folhas & $\begin{array}{l}\text { Matéria } \\
\text { orgânica }\end{array}$ & pH & Hifas & Vesículas & $\begin{array}{c}\text { Esporos } \\
\text { totais }\end{array}$ & Arbúsculos \\
\hline Altura & 1,00 & $0,94 *$ & $0,91 *$ & $0,51 *$ & 0,42 & 0,14 & 0,05 & $-0,42$ & 0,18 \\
\hline Circunferência & $0,94 *$ & 1,00 & $0,92 *$ & 0,35 & 0,36 & 0,12 & 0,06 & $-0,58 *$ & 0,25 \\
\hline Folhas & $0,91 *$ & $0,92 *$ & 1,00 & 0,32 & $0,56 *$ & 0,17 & 0,08 & $-0,45 *$ & 0,13 \\
\hline $\begin{array}{l}\text { Matéria } \\
\text { orgâníca }\end{array}$ & $0,51 *$ & 0,35 & 0,32 & 1,00 & 0,16 & $-0,06$ & $-0,10$ & 0,04 & 0,19 \\
\hline $\mathrm{Ph}$ & 0,42 & 0,36 & $0,56 *$ & 0,16 & 1,00 & 0,28 & 0,02 & $-0,08$ & 0,18 \\
\hline Hifas & 0,14 & 0,12 & 0,17 & $-0,06$ & 0,28 & 1,00 & $0,62 *$ & $-0,12$ & 0,09 \\
\hline Vesículas & 0,05 & 0,06 & 0,08 & $-0,10$ & 0,02 & $0,62 *$ & 1,00 & $-0,09$ & 0,21 \\
\hline Esporos totais & $-0,42$ & $-0,58 *$ & $-0,45^{*}$ & 0,04 & $-0,08$ & $-0,12$ & $-0,09$ & 1,00 & $-0,11$ \\
\hline Arbúsculos & 0,18 & 0,25 & 0,13 & 0,19 & 0,18 & 0,09 & 0,21 & $-0,11$ & 1,00 \\
\hline
\end{tabular}

*Significância do teste com probabilidade p-valor $<0,05$.

Tabela 3. Comparação, em casa de vegetação, do desempenho de plântulas de Schizolobium amazonicum mantidas 45 dias sob as condições de controle (somente terra), solo adubado com NPK 10 - 28 - 20 e inoculação de 30 esporos de FMA por vaso.

\begin{tabular}{lcccccccc}
\hline \multirow{2}{*}{ Tratamento } & \multicolumn{2}{c}{ Altura } & \multicolumn{2}{c}{$\mathbf{N}^{\mathbf{0}}$ de folhas } & \multicolumn{2}{c}{ Peso raiz } & \multicolumn{2}{c}{ Peso aérea } \\
\cline { 2 - 9 } & Média & $\mathbf{C V ( \% )}$ & Média & $\mathbf{C V}(\%)$ & Média & $\mathbf{C V}(\%)$ & Média & $\mathbf{C V ( \% )}$ \\
\hline NPK & 17 & 12,33 & 7,17 & 5,96 & 0,50 & 55,03 & 0,84 & 23,11 \\
CONT & 17,83 & 11,98 & 7,50 & 51,81 & $0,56^{\text {ns }}$ & 43,86 & $1,04^{\text {ns }}$ & 24,72 \\
FMA & $20,67^{*}$ & 6,61 & $10,17^{\text {ns }}$ & 21,01 & 0,40 & 0,40 & 1,00 & 46,80 \\
\hline CV (\%) & 13,01 & & 46,25 & & 47,27 & & 32,33 & \\
\hline
\end{tabular}

*Significativo a $5 \%$ de probabilidade no teste de Duncan. CV = coeficiente de variação.

\section{Discussão}

Os parâmetros mais relevantes na cultura do Paricá são a altura e a circunferência, por estarem diretamente ligados à produtividade, bem como o número de folhas que, na fase inicial do plantio promove o sombreamento e o controle natural das plantas invasoras, evitando assim prejuízos à cultura proporcionados principalmente por cipós e diminuindo os custos com manutenção. Estes fatores apresentaram neste estudo correlações positivas com os dados do solo referentes a pH e teor de matéria orgânica. Esses resultados corroboram a informação de que o solo com maior teor de matéria orgânica e $\mathrm{pH}$ próximo do neutro favorece as plantas amazônicas, cuja nutrição mineral depende da reciclagem dos restos da fauna e flora (Ferreira et al., 2006). As correlações observadas entre altura, diâmetro e número de folhas foram negativas com o número de esporos no solo.

Alguns pesquisadores sugerem, com relação às estruturas fúngicas na interação FMA, que o elevado número de esporos no solo indica considerável nível de estresse (Soares et al., 2007). Uma vez que as amostras de solo colhidas em plantas com maiores diâmetros, alturas e número de folhas apresentaram menos esporos que as amostras colhidas em plantas com menores valores, fica a sugestão de que o número maior de esporos de FMA indica algum desequilíbrio e que este se traduz, no caso da cultura de $S$. amazonicum em menor crescimento da planta. Ainda de acordo com a literatura, as estruturas fúngicas vesículas e hifas são indicadoras de interação vantajosa (Bago et al., 2000; Nielsen et al., 2002). Neste trabalho, as correlações entre as características desejadas da planta e os números de hifas e vesículas por centímetro de raiz não expressaram correlação significativa. No entanto, suas correlações negativas com esporos no solo, reforçam a compreensão de interação benéfica ao sistema solo-planta.

Segundo Smith \& Read (1997), uma planta cujas raízes estão ocupadas por fungos micorrízicos, ainda que não leve vantagens diretas, está protegida de patógenos que poderiam ocupar os mesmos sítios. Outros 
microrganismos do solo se beneficiam das atividades dos FMA e a cultura é beneficiada. Em arbóreas leguminosas nodulíferas, Jesus et al. (2005) observaram aumentos significativos em crescimento e fixação biológica de nitrogênio quando na presença de FMA. Segundo os autores, a maior disponibilidade de fósforo e outros elementos que a colonização micorrízica representa é fator decisivo para o sucesso da fixação biológica de nitrogênio, processo reconhecidamente dispendioso em termos energéticos.

Apesar de não formar nódulos, S. amazonicum pode, quando associado a FMA, apresenta maior aporte de nitrogênio proporcionado por fixadores de $\mathrm{N}$ de vida livre beneficiados pelo efeito micorrizosfera como demonstrado por Siviero et al. (2008). Apesar de se tratar de plantas bastante diferentes, paricá e leucena, Lins et al. (2007) encontraram colonização espontânea por fungos do gênero Glomus na caatinga e, ao separar os esporos e inocular em plântulas de Leucena leucocefala em vasos com solo natural e solo impactado por mineração de cobre, observaram a presença dos fungos FMA fez com que desaparecessem as diferenças entre as plantas cultivadas nas duas condições. Na região do presente estudo, o solo é agredido por sucessivas queimadas em pastagens que ocuparam o espaço deixado por florestas devastadas pela atividade madeireira nas décadas de 1970 e 1980 . Assim como na caatinga, essa região sofre secas intensas em um período do ano e, possivelmente, este seja o fator determinante do sucesso dos fungos FMA nativos em neutralizar os efeitos da mineração (Lins et al., 2007) e do melhor desempenho das plantas de $S$. amazonicum colonizadas por FMA nativos nos solos degradados do Pará. O aumento discreto na produtividade, descrito por Siviero et al. (2008) pode ser ampliado se ambos, fungos micorrízicos e bactérias fixadoras de $\mathrm{N}$ forem selecionados nas áreas da Floresta Amazônica onde S. amazonicum cresce espontaneamente. Os dados obtidos com o experimento em casa de vegetação encorajam a utilização de FMA em mudas de Paricá, uma vez que resultou em aumento da altura da planta e houve discreta diminuição na biomassa do sistema radicular. Este efeito pode estar relacionado ao papel que as hifas de FMA desempenham na associação que é explorar o solo, trazendo às raízes nutrientes já absorvíveis. Resultado semelhante quando da inoculação de FMA em espécies arbóreas é descrito por Vandressen et al. (2007). A diminuição da biomassa radicular pode ser em razão do desvio de metabólitos para o componente fúngico da simbiose ou mesmo para compensar o aumento na altura da parte aérea das plantas, o que neste caso seria muito bom para o cultivo comercial da espécie.

\section{Conclusões}

Schizolobium amazonicum estabelece relação simbiótica com fungos micorrízicos arbusculares de diversas espécies. Existe correlação entre o estado fisiológico da planta e o número de estruturas fúngicas por centímetro de raiz. $\mathrm{O}$ aspecto positivo desta simbiose depende de outros fatores ambientais como o $\mathrm{pH}$ do solo e a quantidade de matéria orgânica. Os esporos de fungo MA isolados do solo, provavelmente Glomus microcarpum, foram capazes de infectar as raízes de plântulas de $S$. amazonicum, refletindo positivamente no seu crescimento em altura. A aplicação de fungos MA selecionados em plântulas de S. amazonicum é uma estratégia vantajosa em cultivos comerciais, uma vez que o ganho em altura nos primeiros meses após o plantio é decisivo para o sucesso da planta.

\section{Agradecimentos}

Agradecemos o apoio recebido da empresa Canto Verde Agroflorestal - Florestadora e Reflorestadora Ltda., pela abertura de seus plantios para a realização desta pesquisa bem como todo o apoio logístico para que as coletas e avaliações pudessem ser realizadas. Agradecemos à bióloga Iane Paula Rego Cunha, pelo apoio na identificação do fungo micorrízico utilizado no experimento em casa de vegetação.

\section{Referências}

ALBINO, U. B. Cultivo de arbóreas na Amazônia: sustentabilidade de solo e clima. In: ENCONTROAMAZÔNICO DEAGRÁRIAS, 4., 2012, Belém, PA. Agricultura familiar: mecanismos de desenvolvimento no cenário amazônico: anais. Belém, PA: UFRA, 2012.

ALBINO, U.; SARIDAKIS, D. P.; FERREIRA, M. C.; HUNGRIA, M.; VINUESA, P.; ANDRADE, G. High diversity of diazotrophic bacteria associated with the carnivorous plant Drosera villosa var. villosa growing in oligotrophic habitats in Brazil. Plant and Soil, The Hague, v. 287, p. 199-207, 2006.

AUGÉ, R. M.; STODOLA, A. J. W.; TIMS, J. E.; SAXTON, A. M. Moisture retention properties of a mycorrhizal soil. Plant and Soil, The Hague, v. 230, p. 87-97, 2001.

BAGO, B.; PFEFFER, P.E.; SHACHAR, H.Y. Carbon metabolism and transport in arbuscular mycorrhizas. Plant Physiology, Waterbury, v. 124, p. 949-957, 2000. 
BALAKRISHNA, R.; BAGYARAG, D. J.; MALLESHA, B. C.; REDDY, B. Selection of efficient VA mycorrhizal fungi for papaya. Biological Agriculture \& Horticulture, Oxon, v. 13, p. 1-6, 1996.

BARBOSA, J.C. Estatística experimental. São Paulo: FCAVUNESP, 2000. 288p..

DUCKE, A. Notas sobre a flora neotrópica II: as leguminosas da Amazônia brasileira. 2. ed. Belém: IAN, 1949. 248 p. (IAN. Boletim técnico, 18),

FERREIRA, S. J. F.; LUIZÃO, J. L.; MIRANDA, S. A. F.; DA SILVA, M. S.; VITAL, A. R. T. Nutrientes na solução do solo em floresta de terra firme na Amazônia Central submetida à extração seletiva de madeira. Acta Amazônica, Manaus, v. 36, n. 1, p. 59-68, 2006.

GERDEMANN, J. W.; TRAPPE, J. M. The Endogonaceae in the Pacific Northwest. [New York]: New York Botanical Garden, 1974. p. 1-76. (Mycologia Memoir, 5).

JARAMILLO-BOTERO, C.; SILVA SANTOS, R. H.; FARDIM, M. P.; PONTES, T. M.; SARMIENTO, F. Produção de serapilheira e aporte de nutrientes de espécies arbóreas nativas em um sistema agroflorestal na zona da mata de minas gerais. Revista Árvore, Viçosa, MG, v. 32, n. 5, p. 869-877, 2008

JESUS, E. C.; SCHIAVO, J. A.; FARIAS, S. M. Dependência de micorrizas para a nodulação de leguminosas arbóreas tropicais. Revista Árvore, Viçosa, MG, v. 29, n. 4, p. 545-552, 2005.

LINS, C. E. de L.; MAIA, L. C.; CAVALCANTE, U. M. T.; SAMPAIO, E. V. de S. B. Efeito de fungos micorrízicos arbusculares no crescimento de mudas de leucaena leucocephala (lam.) de wit. em solos de caatinga sob impacto de mineração de cobre. Revista Árvore, Viçosa, MG, v. 31, n. 2, p. 355-363, 2007.

MONTGOMERY, D. C. Design and analysis of experiments. 5th ed. New York: Wiley, 2001.

NIELSEN, J.S.; JONER, E.J.; DECLERCK, S.; OLSSON, S.; JAKOBSEN, I. Phospho-imaging as a tool for visualization and noninvasive measurement of $\mathrm{P}$ transport dynamics in arbuscular mycorrhizas. Plant Physiology, Waterbury, v.154, p.809-819, 2002.
PHILIPS, D. A.; HAYMAN, D. S. Improved procedures for clearing roots and staining parasitic and vesicular-arbuscular mycorrhizal fungi for rapid assessment of infection. Transactions of the British Mycological Society, Cambridge, v. 55, p.158-161,1970.

R DEVELOPMENT CORE TEAM. R: a language and environment for statistical computing. Vienna: R Foundation for Statistical Computing, 2006. Disponível em: <http://www.R-project.org>. Acesso em: 20 out. 2010.

RONDON, E. V. Produção de biomassa e crescimento de árvores de Schizolobium amazonicum (Huber) Ducke sob diferentes espaçamentos na região de mata. Revista Árvore, Viçosa, MG, v. 26, n. 5, p. 573-576, 2002.

SIVIERO, M. A.; MOTTA, A. M.; LIMA, D. S.; BIROLLI, R. R.; HUH, S. Y.; SANTINONI, I. A.; MURATE, L. S.; DE CASTRO, C. M. A.; MIYAUCHI; M. Y. H.; ZANGARO, W.; NOGUEIRA, M. A.; ANDRADE, G. Interaction among N-fixing bacteria and AM fungi in Amazonian legume tree (Schizolobium amazonicum) in field conditions. Applied Soil Ecology, Amsterdam, v. 39, p. 144-152, 2008.

SMITH, S. E.; READ, D. J. Mycorrhizal symbiosis. California: Academic Press, 1997. 506 p.

SOARES, C. R. F. S.; SIQUEIRA, J. O.; CARVALHO, J. G.; GUILHERME, L. R. G. Nutrição fosfática e micorriza arbuscular na redução da toxicidade de cádmio em trema [Trema micrantha (L.) Blum.]. Revista Árvore, Viçosa, MG, v. 31, n. 5, p. 783-792, 2007.

VANDRESSEN, J.; NISHIDATE, F. R.; TOREZAN, J. M. D.; ZANGARO, W. Inoculação de fungos micorrízicos arbusculares e adubação na formação e pós-transplante de mudas de cinco espécies arbóreas nativas do sul do Brasil. Acta Botanica Brasilica, Brasília, DF, v. 21, n. 4, p. 753-765, 2007.

ZANGARO, W.; NISIZAKI, S. M. A.; DOMINGOS, J. C. B.; NAKANO, E. M. Mycorrhizal response and successional status in 80 woddy species from south Brazil. Journal of Tropical Ecology, New York, v. 19, p. 315-324, 2003.

ZAR, J. H. Biostatistical analysis. 4th ed. Englewood Cliffs: Prentice Hall, 1999. 
